\title{
Article
}

\section{Burning behaviour of rainscreen façades}

Jones, Nicola, Peck, Gabrielle, Mckenna, Sean Thomas, Glockling, Jim L.D., Harbottle, John, Stec, Anna A and Hull, T Richard

Available at http://clok.uclan.ac.uk/35249/

Jones, Nicola ORCID: 0000-0002-1985-5266, Peck, Gabrielle, Mckenna, Sean Thomas, Glockling, Jim L.D., Harbottle, John, Stec, Anna A ORCID: 0000-00026861-0468 and Hull, T Richard ORCID: 0000-0002-7970-4208 (2021) Burning behaviour of rainscreen façades. Journal of Hazardous Materials, 403 . p.

123894. ISSN 0304-3894

It is advisable to refer to the publisher's version if you intend to cite from the work.

http://dx.doi.org/10.1016/j.jhazmat.2020.123894

For more information about UCLan's research in this area go to http://www.uclan.ac.uk/researchgroups/ and search for <name of research Group>.

For information about Research generally at UCLan please go to http://www.uclan.ac.uk/research/

All outputs in CLoK are protected by Intellectual Property Rights law, including Copyright law. Copyright, IPR and Moral Rights for the works on this site are retained by the individual authors and/or other copyright owners. Terms and conditions for use of this material are defined in the policies page.

\section{CLoK}

Central Lancashire online Knowledge www.clok.uclan.ac.uk

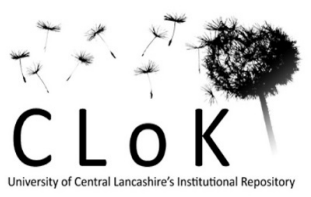




\section{Burning behaviour of rainscreen façades}

Nicola Jones ${ }^{1}$, Gabrielle Peck ${ }^{1}$, Sean T McKenna ${ }^{1}$, Jim L. D. Glockling ${ }^{2}$, John Harbottle ${ }^{2}$, Anna A. Stec ${ }^{1}$, and T. Richard Hull ${ }^{1 *}$.

1. Centre for Fire and Hazard Science, University of Central Lancashire, Preston, PR1 2HE, UK

2. Fire Protection Association, London Road, Moreton in Marsh, Gloucestershire, GL56 ORH, UK

* corresponding author trhull@uclan.ac.uk

\section{Abstract}

Four reduced-height (5 m) BS 8414-1 façade flammability tests were conducted, three having mineral-filled aluminium composite material (ACM-A2) with polyisocyanurate (PIR) and phenolic (PF) foam and stone wool (SW) insulation, the fourth having polyethylene-filled ACM (ACM-PE) with PIR insulation. Each façade was constructed from a commercial façade engineer's design, and built by practising façade installers. The ACM-PE/PIR façade burnt so ferociously it was extinguished after $13.5 \mathrm{~min}$, for safety. The three ACM-A2 cladding panels lost their structural integrity, and melted away from the test wall, whereupon around $40 \%$ of both the combustible PIR and PF insulation burnt and contributed to the fire spread. This demonstrates why all façade products must be noncombustible, not just the outer panels. For the three ACM-A2 tests, while the temperature in front of the cavity was independent of the insulation, the temperatures within it varied greatly, depending on the insulation. The system using PF/A2 allowed fire to break through to the cavity first, as seen by a sharp increase in temperature after $17 \mathrm{~min}$. For PIR/A2, the temperature increased sharply at 22 minutes, as the panel started to fall away from the wall. For SW/A2, no rapid temperature rise was observed.

Keywords: Fire; BS 8414; cavity; polyisocyanurate; PIR; phenolic; stone wool; aluminium composite material; ACM; tower blocks.

\section{Introduction}

Immediately following the Great Fire of London, the London Building Act (1667) restricted the use of combustible materials, such as wood, on building exteriors. In the UK, most buildings were constructed from non-combustible materials for the following 400 years. The 1960s brought a significant rise in the number of tall concrete buildings, alongside the replacement of wood with more combustible, synthetic polymers, derived from crude oil, as non-structural construction materials. In the UK there were no major revisions of the Building Regulations covering fire safety (Approved Document B (Fire Safety)(AD B)) from the 2000 edition to the 2019 revision [1]; while there were five major revisions of the equivalent document covering insulation (Approved Document L: Conservation of Fuel and Power), with each edition specifying improved thermal performance. However, a significant minor change was made in 2006 when the restrictions on the use of combustible materials on the outside of tall buildings were relaxed. This permitted the use of combustible façade systems on buildings over $18 \mathrm{~m}$, which met the criteria set out in BR 135 [2] when tested in BS 8414 [3]. To ensure that occupants in high rise buildings are as safe from fire as those in two-storey dwellings, $A D$ B requires compartmentation of individual apartments (with fire resistant walls, floors, ceilings and doors etc.). The use of combustible façades undermines that 
strategy by allowing fire spread up the outside of the building, as occurred during the Grenfell Tower fire, which killed 72 people in London in 2017. Since the Grenfell Tower fire in 2017, AD B has been rewritten for improved clarity, and is undergoing review for improved fire safety. In December 2018, independent of $A D B$, but after a brief report of this study [4] had been submitted to government, the Building Regulations were changed to introduce a non-retrospective ban on combustible products on the exterior faces of tall residential buildings in England.

A rainscreen façade system comprises a thin outer panel (also known as a "rainscreen"), an air gap, to prevent moisture penetration, and an inner layer to provide thermal insulation. The fire behaviour of common rain screen facade products has been reported elsewhere [5]. The outer panel can be metal (e.g. zinc, steel or aluminium), but the higher heat capacity of the metal encourages condensation, leading to unsightly mineral deposits, so lower thermal capacity alternatives are often preferred. These include aluminium composite material (ACM), high-pressure laminate (HPL), and mineral fibre boards. ACM consists of two thin sheets of aluminium $(\sim 0.5 \mathrm{~mm})$ sandwiching a $3 \mathrm{~mm}$ layer of polymer (usually polyethene (PE)), PE filled with metal hydroxide fire retardant (FR), or predominantly non-combustible inorganic composite or metallic filling (meeting Euroclass A2 (A2)).

Insulated rainscreen façade systems are widely used for refurbishment of concrete-faced buildings. In the UK, many buildings were refurbished with combustible foam insulation and aluminiumpolyethylene composite material (ACM-PE), separated by a cavity (Figure 1) covering the exterior of the building. In order to prevent moisture accumulation within the façade, it is designed so that air can freely circulate through the cavity. Unfortunately, this also allows fire to propagate within the cavity, with the cavity acting like a chimney drawing the flame upwards. The cavity is a key factor in the fire behaviour of rain screen facades. To address this AD B states that all cavities must be firestopped with cavity barriers at specified intervals (typically at the boundaries of each apartment and around windows). For a vertically continuous façade this may be effected with a horizontal layer of non-combustible stone wool insulation, with an intumescent strip facing the air-gap, which, in the event of a fire, should swell and seal the gap. This is illustrated in Figure 1. To be effective at firestopping, these strips must be installed correctly, and the outer panel must be resilient in the event of fire, in order to provide a face on which to form a seal.

It has been shown [6] that for polyurethane foam insulation and gypsum board, a $25 \mathrm{~mm}$ wide cavity limited the flame spread to $1-2 \mathrm{~m}$, but a $40 \mathrm{~mm}$ cavity allowed flame spread throughout a test façade. When expanded and extruded polystyrene (EPS and XPS) and gypsum board were used, the polystyrene foam melted and receded, resulting in a widening of the cavity. It has been suggested that the worst case for upward fire spread is a cavity of $50 \mathrm{~mm}$ with limited flame penetration for a cavity of $25 \mathrm{~mm}$ or narrower [6]. Despite this, cavities in the UK are usually $50 \mathrm{~mm}$ wide, with a 25 $\mathrm{mm}$ gap between the front face of the cavity barrier and the façade panels.

Following the Grenfell Tower fire, Babrauskas [7] argued strongly for science to underpin the largescale fire tests used to ensure the fire safety of façades. Most large-scale tests are purely empirical and provide little data, such as heat flux, for engineers to use to ensure fire safety. In addition, they only represent the test scenario itself, not the real building. Babruaskas pointed out that numerous studies of façade fire disasters have been written, but none had been related to the tests used to approve the façade systems in the first place. 


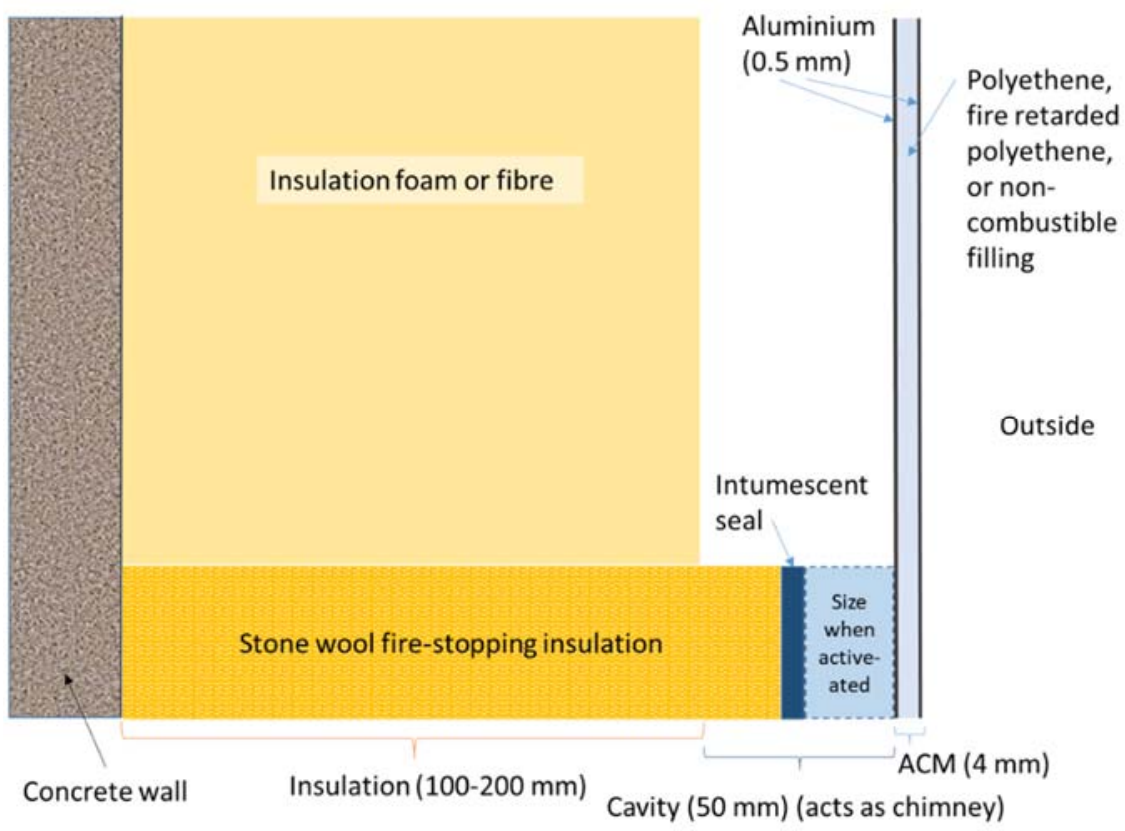

Figure 1 Typical ACM Rainscreen Façade Insulation system

Following the Grenfell Tower fire, the UK government's Department of Communities and Local Government (DCLG) asked the BRE test laboratory to undertake a series of tests on insulated rainscreen façade systems faced with different classes of ACM and insulation, using the BS 8414-1 test. The test results are publicly available [Section 3.5], and summarised in Table 1.

Table 1 Summary of DCLG test results

\begin{tabular}{lll}
\hline Products in test & DCLG test result (BS 8414-1) & \\
\hline ACM-PE + PIR & Test stopped (9 min) & Fail \\
ACM-PE + SW & Test stopped (7 min) & Fail \\
ACM-FR + PIR & Test stopped (25 min) & Fail \\
ACM-FR + PF & Test stopped (28 min) & Fail \\
ACM-FR + SW & Test completed, criteria met & Pass \\
ACM-A2 + PIR & Test completed, criteria met & Pass \\
ACM-A2 + SW & Test completed, criteria met & Pass \\
\hline
\end{tabular}

These test results indicated that the use of ACM-A2 ensured the fire safety of tall buildings covered in combustible insulation, since they met the AD B criteria. A critique of the BS 8414 standard, the BR 135 criteria, the DCLG tests, and differences between facades constructed for fire tests and normal building industry practice has been reported elsewhere [8]. The aim of this work was to provide experimental data to inform the fire safety strategy for tall buildings. There were two objectives: 
1. to assess the extent to which non-combustible ACM-A2 was able to protect underlying combustible insulation in a rainscreen façade; and

2. to assess the difference between façades designed and constructed specifically for fire tests and those designed and built using normal, but carefully supervised construction industry practice.

The experimental part of the current work was conducted after the DCLG tests, but before the UK government announced any regulatory change following the Grenfell fire.

A series of façade systems were constructed using a reduced height BS 8414-1 rig (5 m), in order to understand the fire behaviour of typical rainscreen façade systems, constructed in accordance with industry standard practice, using their performance in a reduced height BS 8414-1 test. A reduced height test was used because of the lack of availability of full-height test facilities due to the high, post-Grenfell demand for BS 8414 tests. The $5 \mathrm{~m}$ test wall was located in a test room with roof and extraction fan at $6 \mathrm{~m}$ height. The inclusion of a kitchen vent into the façade provides an example of the effect of additional features found in real buildings as part of large-scale façade tests, which has been emphasised previously $[9,10]$.

\section{Experimental}

\subsection{Materials}

Four rainscreen façade combinations of insulation and cladding panels were investigated in a reduced height BS 8414-1 test, shown in Table 2.

ACM-PE, with PF and PIR insulation are reported to have been used extensively in UK building refurbishments [11]. ACM-A2 is the only type of $A C M$ cladding panel currently allowed on new or newly refurbished residential buildings over $18 \mathrm{~m}$ in the UK.

Table 2 Combinations of insulation and cladding panels

\begin{tabular}{lll}
\hline Abbreviation & Insulation & External panel \\
\hline SW/A2 & Stone wool & ACM-A2 (mineral core) \\
PF/A2 & Phenolic foam & ACM-A2 (mineral core) \\
PIR/A2 & Polyisocyanurate foam & ACM-A2 (mineral core) \\
PIR/PE & Polyisocyanurate foam & ACM-PE (polyethene core) \\
\hline
\end{tabular}

The ACM-A2 is comprised of two sheets of aluminium ( $0.5 \mathrm{~mm}$ thick) with a mineral-filled core, containing a small $(<5 \%)$ amount of organic binder [5]. On 31 December 2018, there were no reports of tower blocks in the UK with ACM-A2 panels (non-combustible). All ACM on tower blocks in the UK was either the most flammable type, PE, or the FR type [11].

In each case, a $50 \mathrm{~mm}$ ventilated cavity separated the ACM from the insulation. Cavity barriers of stone wool faced with an intumescent strip were installed. SW/A2 may be considered as a control, since all aspects of the facade system were of limited combustibility (minimum Euroclass A2).

$100 \mathrm{~mm}$ thick slabs of PIR and phenolic foam insulation were used for the tests. As stone wool needs to be thicker to achieve the same thermal insulation as part of a building façade, $180 \mathrm{~mm}$ thick slabs were used. 


\subsubsection{Materials selection}

Three plastic insulation foams, two phenolic foams (Kingspan K15 and Xtratherm SR/RS) and polyisocyanurate foam (PIR) (Celotex RS 5000) were reported to have passed the BS 8414 test as part of a rainscreen façade system [12], although the certification for two of the three foams has subsequently been withdrawn. The phenolic foam for which the certification was still valid was used for the test. The PIR product previously certified as suitable for rainscreen facades on buildings over $18 \mathrm{~m}$ (PIR-RS), could not be obtained. A similar, commercially available PIR (PIR-com), from the same manufacturer was used instead. Analysis of both PIR foams by diamond ATR-FTIR showed that they were chemically similar. Table 3 shows physical and combustion properties of PIR-RS and PIR-com showing that PIR-com was a suitable substitution.

Table 3 Comparison of properties of PIR-RS and PIR-com

\begin{tabular}{|c|c|c|c|c|c|c|c|}
\hline & \multirow[b]{2}{*}{$\begin{array}{l}\text { Density } \\
\left(\mathrm{kg} \mathrm{m}^{-3}\right)\end{array}$} & \multirow[b]{2}{*}{$\begin{array}{l}\text { Heat of } \\
\text { Combustion } \\
\left(\mathrm{MJ} \mathrm{kg}^{-1}\right)\end{array}$} & \multicolumn{3}{|c|}{ Elemental Composition (\%) } & \multicolumn{2}{|c|}{ Cone calorimetry } \\
\hline & & & C & $\mathrm{H}$ & $\mathrm{N}$ & $\begin{array}{l}\text { Peak Heat } \\
\text { Release Rate } \\
\left(\mathrm{kW} \mathrm{m}^{-2}\right)\end{array}$ & $\begin{array}{l}\text { Total Heat } \\
\text { Released } \\
\left(\mathrm{MJ} \mathrm{m}^{-2}\right)\end{array}$ \\
\hline PIR-RS & $35.0^{[5]}$ & 18.3 & 66.1 & 5.3 & 7.3 & 107 & 15.6 \\
\hline PIR-com & 36.7 & 20.5 & 65.4 & 5.1 & 7.9 & 100 & 14.9 \\
\hline
\end{tabular}

The heat of combustion was obtained by microscale combustion calorimetry (MCC) (Method B) [13]. Elemental composition was obtained by elemental analysis using CHNS (Thermo Scientific Flash 2000 Organic elemental analyser). Cone calorimetry was carried out according to ISO 5660 [14] at a heat flux of $50 \mathrm{~kW} \mathrm{~m}^{-2}$ on samples measuring $100 \times 100 \times 20 \mathrm{~mm}$ thick, without the aluminium foil facing. The upper retaining frame was not used.

\subsection{Façade assembly}

The tests were conducted on an L-shaped test wall according to BS 8414-1 [15] of reduced height of $5 \mathrm{~m}$. The standard-construction masonry block test wall was built inside a $10 \mathrm{~m} \times 10 \mathrm{~m} \times 6 \mathrm{~m}$ high, specialised fire test facility. The façade design was based on typical building project designs with installation of each façade system carried out by professional installers, following standard building practice.

Each façade was built-up from the wall outwards as follows: a $100 \mathrm{~mm}$ layer of insulation $(180 \mathrm{~mm}$ in the case of stone wool), a $50 \mathrm{~mm}$ cavity, and a $4 \mathrm{~mm}$ thick ACM panel, attached with screws to aluminium rails. Cavity barriers were installed according to the manufacturers' instructions, with a $25 \mathrm{~mm}$ gap to the inner face of the ACM cladding panels. Thermocouples were located $2.5 \mathrm{~m}$ above the top of the combustion chamber, in the centre of the front face and the wing, as specified in BS 8414 (level 1), at the following positions: TC1 and TC4 (50 mm in front of surface), TC2 (midpoint of cavity) and TC3 (midpoint of insulation). A diagram of the test wall including the cavity barrier and thermocouple locations, and a photograph of the assembled wall, can be seen in Figure 2 . 


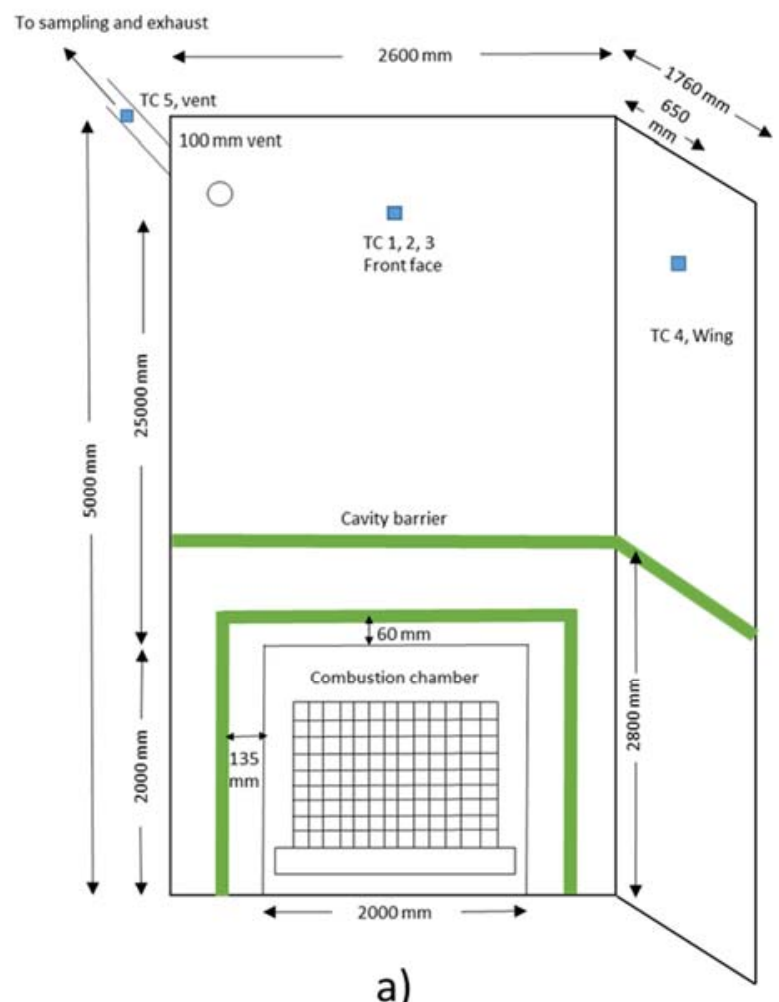

a)

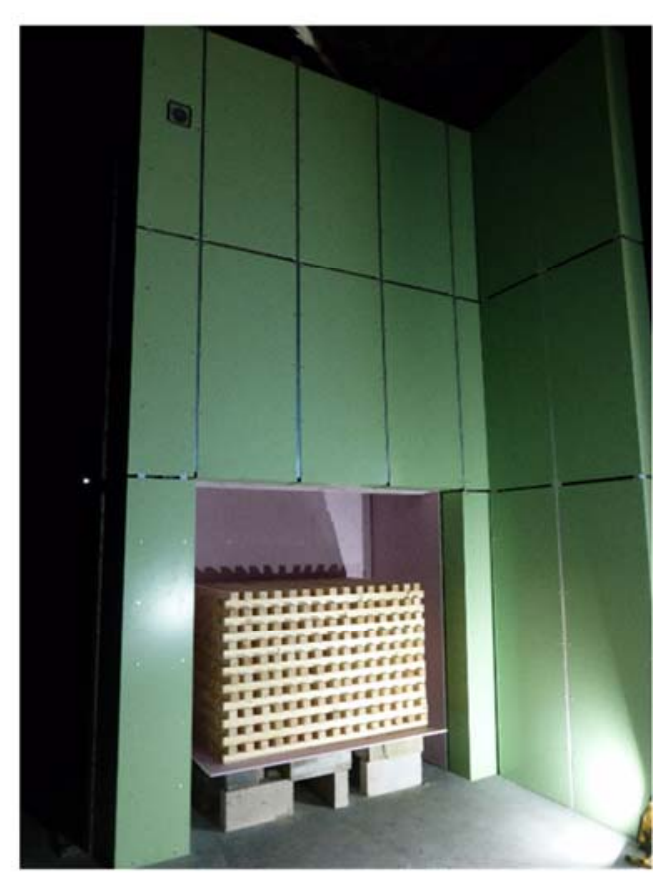

b)

Figure 2 a) Diagram of the test wall, showing cavity barrier (green) and thermocouple locations and b) photograph of completed wall

The ceiling of the test room was fitted with a $2.5 \mathrm{~m} \times 2.5 \mathrm{~m}$ pumped extraction system for removal of smoke and exhaust gases. Sampling lines were installed within the extraction duct with probes used to measure the oxygen concentration, velocity and temperature of gases in order to calculate the heat release. An opening of $2 \mathrm{~m}^{2}$ at floor level allowed air ingress as shown in Figure 3.

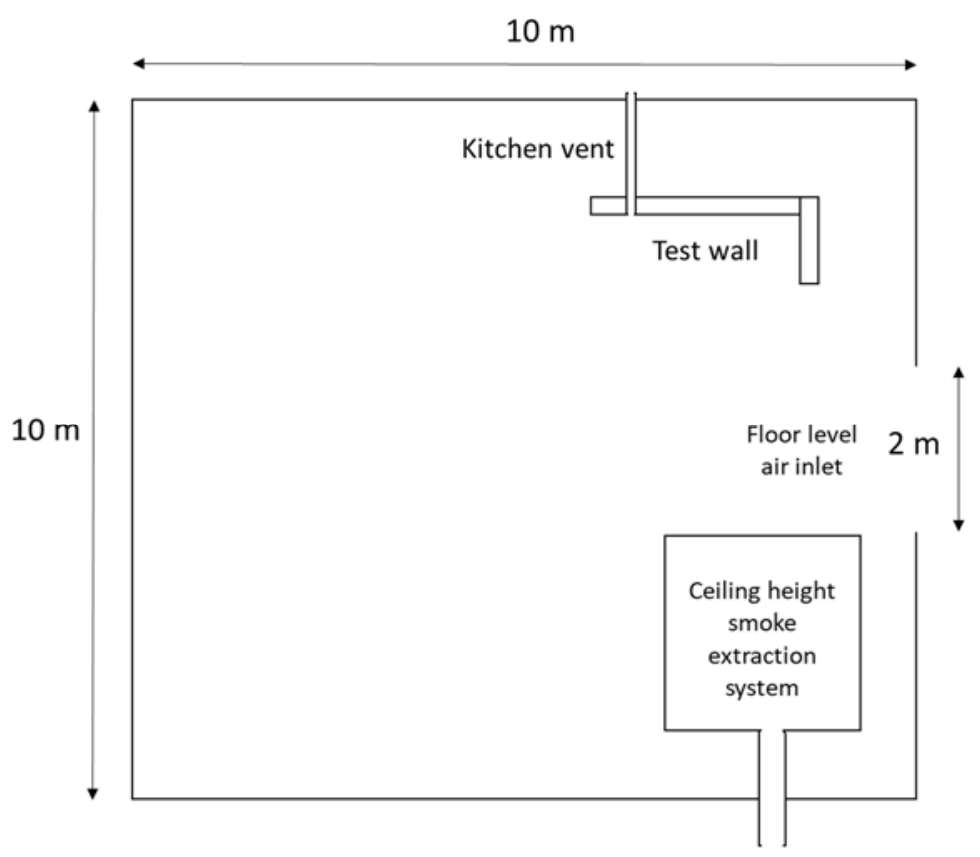

Figure 3 Plan view of the test room 
A 'kitchen vent' was included in the installation, since they are a common feature of modern building facades, but there is no requirement to include them in the BS 8414 test. The vent consisted of a 100 $\mathrm{mm}$ diameter galvanised steel pipe, which was flush with the front face of the insulation, and faced by a $150 \mathrm{~mm} \times 150 \mathrm{~mm}$ steel grille on the outside of the ACM panel Figure 2 (b) and Figure 3. A thermocouple (TC5), a McCaffrey probe to measure flow, and gas sampling lines were added to the vent duct. A cross-section of the test wall, showing the position of the vent and thermocouples is shown in Figure 4.

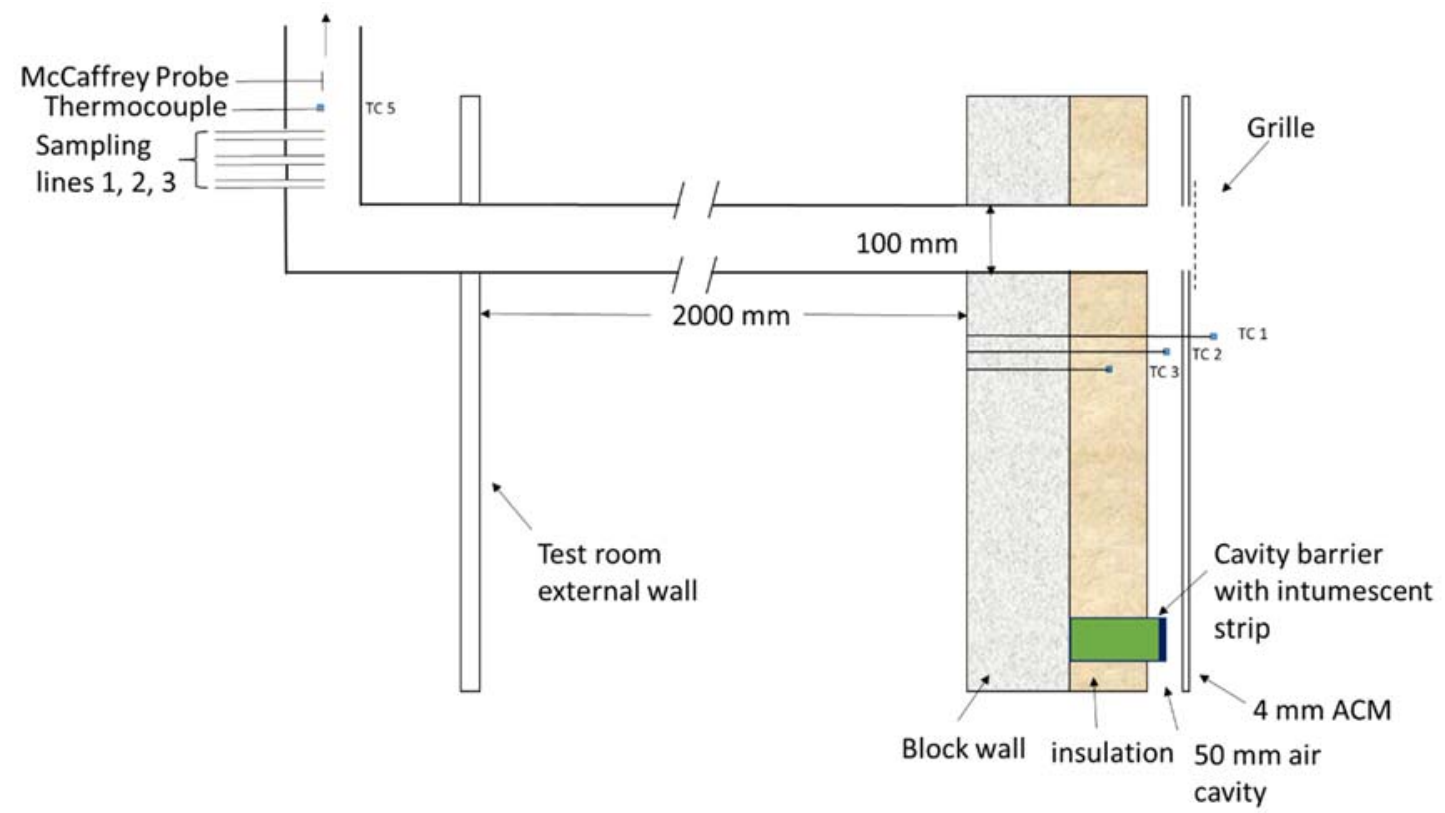

Figure 4 Cross-section of the test wall and external vent

The fuel source and ignition followed the BS 8414 protocol. This used a standard $3 \mathrm{MW}(300 \mathrm{~kg}$ ) wood crib, ignited using 16 strips soaked in white spirit, with 14 running from the front to back, one layer above the base of the crib.

\section{Results and Discussion}

In accordance with the BS 8414 test protocol, the wood cribs were extinguished after 30 min, but the facade allowed to continue to burn for a further $30 \mathrm{~min}$. In the case of the PIR/PE test, the fire growth was extremely rapid and the wood crib was extinguished after $13.5 \mathrm{~min}$. This decision was based on safety concerns for personnel and the test building structure, due to the ferocity of the fire.

\subsection{Panel Performance}

In all of the tests, some ACM panels, both $\mathrm{A} 2$ and $\mathrm{PE}$, either melted, or burnt away from the wall and failed to protect the insulation from the burning wood crib. Aluminium melts at $660{ }^{\circ} \mathrm{C}$, but loses strength around $500{ }^{\circ} \mathrm{C}$. Many fires are significantly hotter than $660^{\circ} \mathrm{C}$, so it is unsurprising that the ACM panels, and the aluminium support rails, failed to maintain the structural integrity of the façade system. After this point, the insulation was exposed to the fire. For each of the three ACM-A2 tests, around $40 \%$ of the ACM has melted or fallen away from the test wall, and another 20 to $40 \%$ was severely damaged. For SW/A2 the exposed insulation remained attached to the wall for the remainder of the test. For PF/A2 and PIR/A2 the exposed insulation began to burn and fell from the 
wall during the test. In both cases the masonry wall was exposed, between the combustion chamber and the top of the façade.

As a result of panel disintegration, the cavity barriers in those locations were ineffectual, failing to stop the spread of flame since they had no surface to seal onto. This is in disagreement with a medium-scale study by Guillaume et al., which found that cavity barriers performed well with ACMA2 [16]. However, in that case the ISO 13785-1 test was followed, using a $100 \mathrm{~kW}$ heat source on a $2.4 \mathrm{~m}$ test rig. Another recent study found that when combustible insulation was used with ACM-A2 panels, twice as many horizontal cavity barriers were required to stop flame spread compared to non-combustible insulation [17].

Figure 5 shows the test walls for the tests using ACM-A2 panels at the end of the test, after the wood crib was extinguished ( $30 \mathrm{~min}$ ) and the fire allowed to continue for $60 \mathrm{~min}$ (from ignition).

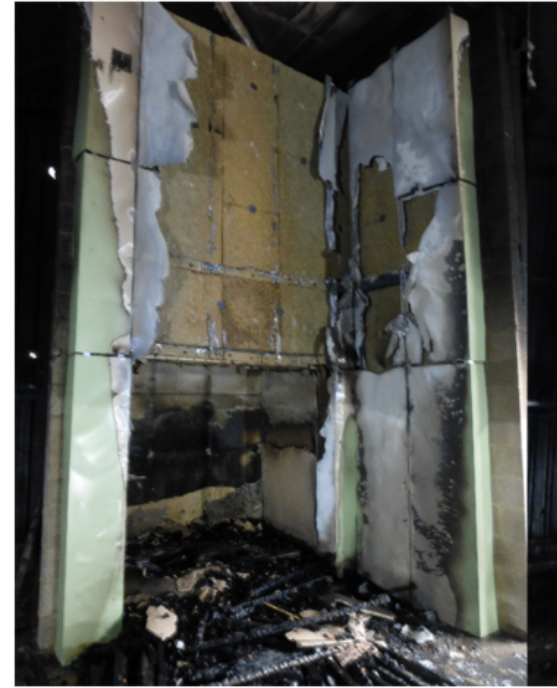

a)

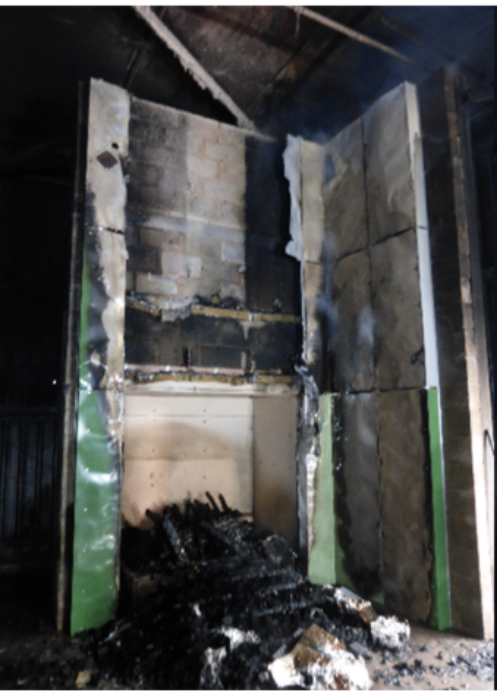

b)

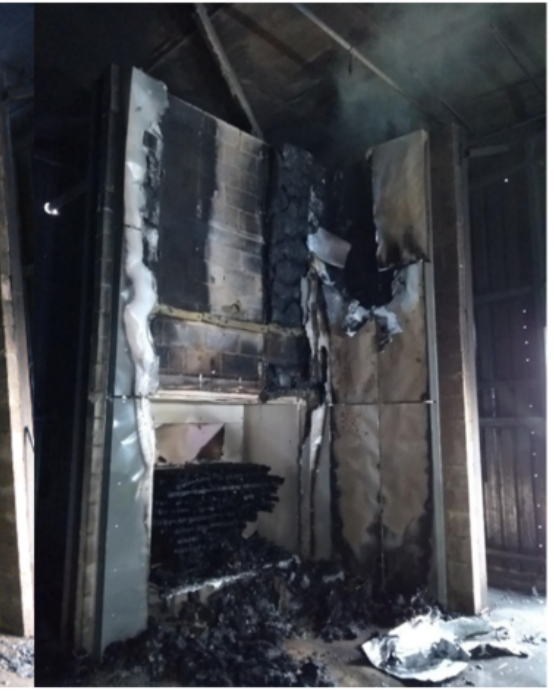

c)

Figure 5 Façade remains after the tests: a) SW/A2, b) PF/A2, c) PIR/A2

\subsection{Temperature Data}

The thermocouple data recorded from TC1 (Figure 2 a), at the centre of the front face of the façade (Figure 6), $2.5 \mathrm{~m}$ above the top of the combustion chamber, and protruding $50 \mathrm{~mm}$ in front of the face of the ACM, show similar fire growth rates for the SW/A2 and PIR/A2 tests, with slightly faster growth rates for the PF/A2 and PIR/PE. This may result from differences in external wind speed and direction, entering the test room through the $2 \mathrm{~m}^{2}$ ground level opening, or the inherent irreproducibility of the BS 8414 wood crib fuel source. At 6 min into the test, the ACM-PE became involved in the fire and the temperature of the PIR/PE test exceeded that of the PF/A2 test. The drop in temperature of the PF/A2 around 18 min probably results from physical movement of the insulation slab to shield the thermocouple (Figure 8). 


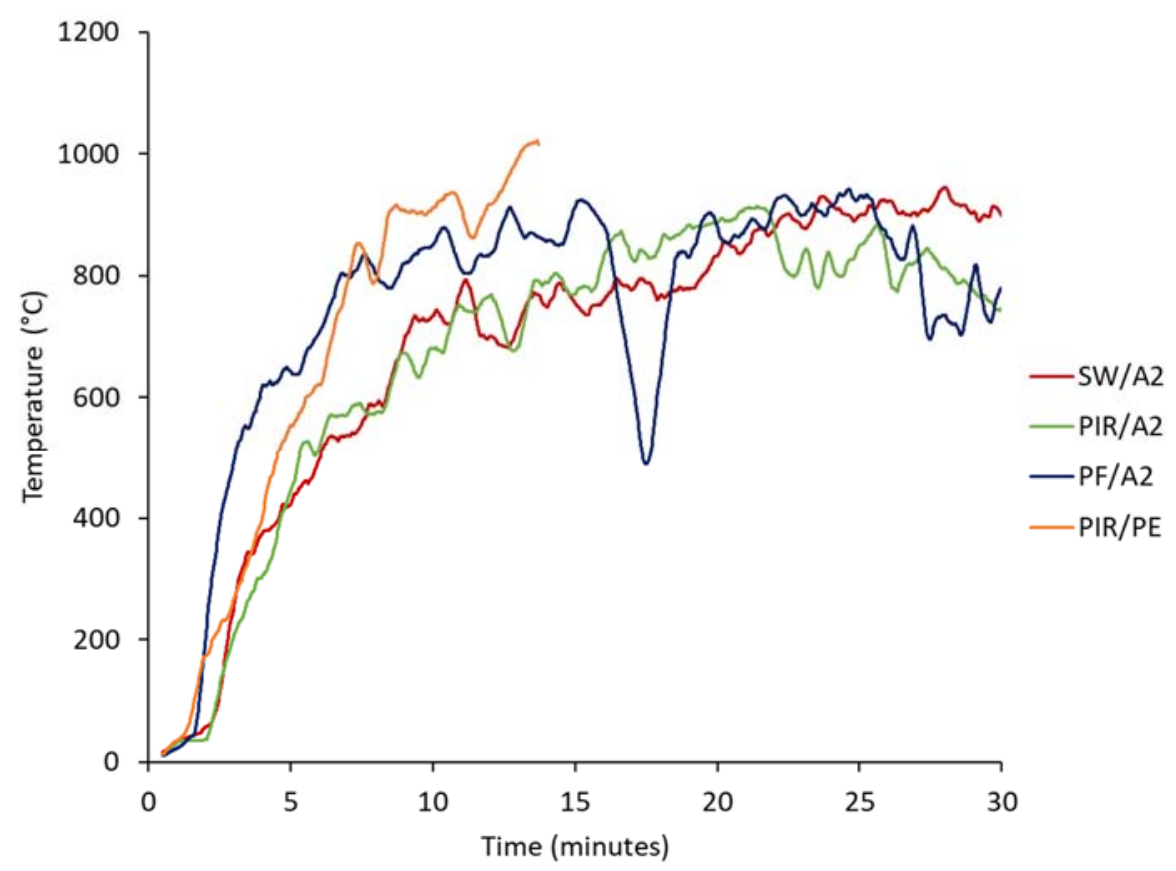

Figure 6 Temperature $50 \mathrm{~mm}$ outside façade, centre front face (TC1)

Figure 7 shows the temperature measured in the centre of the cavity, $2.5 \mathrm{~m}$ above the combustion chamber. This shows similar behaviour to the external thermocouple but provides insight into the behaviour within the façade. In general, at $650^{\circ} \mathrm{C}$ the temperature variation is more erratic, corresponding to melting of the aluminium panels and brackets (at $660^{\circ} \mathrm{C}$ ) and exposing the thermocouple directly to the flame. The greater fire growth of the PIR/PE façade is evident before 5 min, and movement of the insulation slabs of PF/A2 (17 min) and PIR/A2 (23 min) appears evident. These times correspond to increases in temperatures of the thermocouples originally located in the mid-point of the insulation, seen in Figure 9. This movement is illustrated in Figure 8.

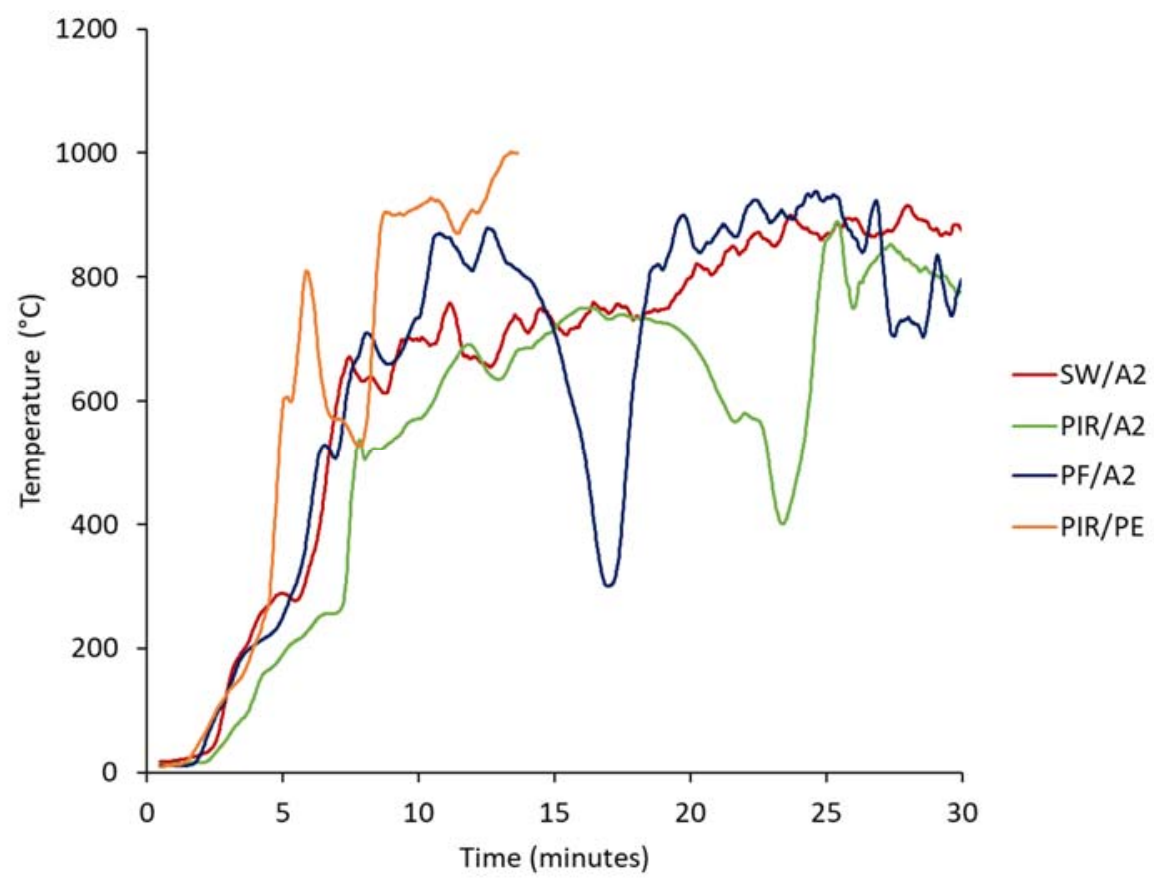




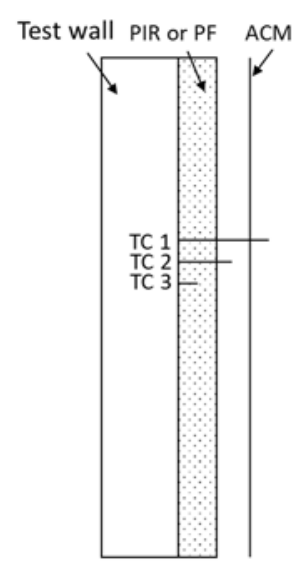

Start of test

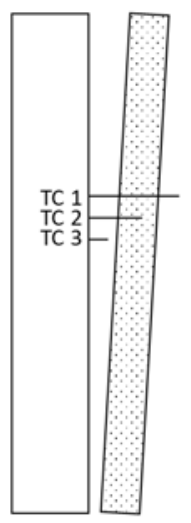

$17 \min (P F)$ $23 \min (\mathrm{PIR})$

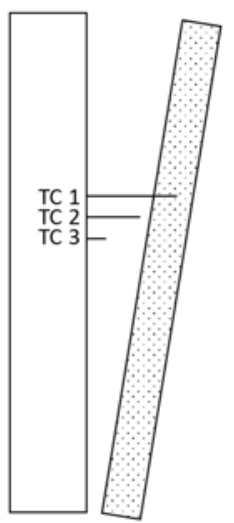

$18 \mathrm{~min}(\mathrm{PF})$

Figure 8 Movement of insulation panel to cover and expose thermocouples

Figure 9 shows the temperatures measured at the midpoint of the insulation, $2.5 \mathrm{~m}$ above the combustion chamber. The data here show much clearer differences between the fire behaviour of the insulation products. The SW/A2 shows an expected progressive temperature increase, rising to $500^{\circ} \mathrm{C}$ in $30 \mathrm{~min}$, the insulation has remained in place, fixed to the wall. The movement of the combustible insulation slabs is also evident from the photographs in Figure 5. The foam insulation panels, which are superior insulators, show interesting three stage burning behaviour. In less than 5 min the temperature reaches $50^{\circ} \mathrm{C}$, then at $6 \mathrm{~min}(\mathrm{PF} / \mathrm{A} 2)$ and $7.5 \mathrm{~min}(\mathrm{PIR} / \mathrm{A} 2)$ the temperature rapidly rises to $\sim 250^{\circ} \mathrm{C}$. Intriguingly, PIR/PE shows no two stage exothermic decomposition, possibly because of consumption of all available oxygen in the cavity by the burning ACM-PE. The temperature of the PIR/A2 and $P F / A 2$ then rises gradually until the insulation falls away from the walls at $17 \mathrm{~min}$ (PF/A2) and $23 \mathrm{~min}$ (PIR/A2) (seen in Figs. 6 to 8). After that, the burnt insulation slab falls away leaving TC 3 completely exposed and the full flame temperature is reached. 


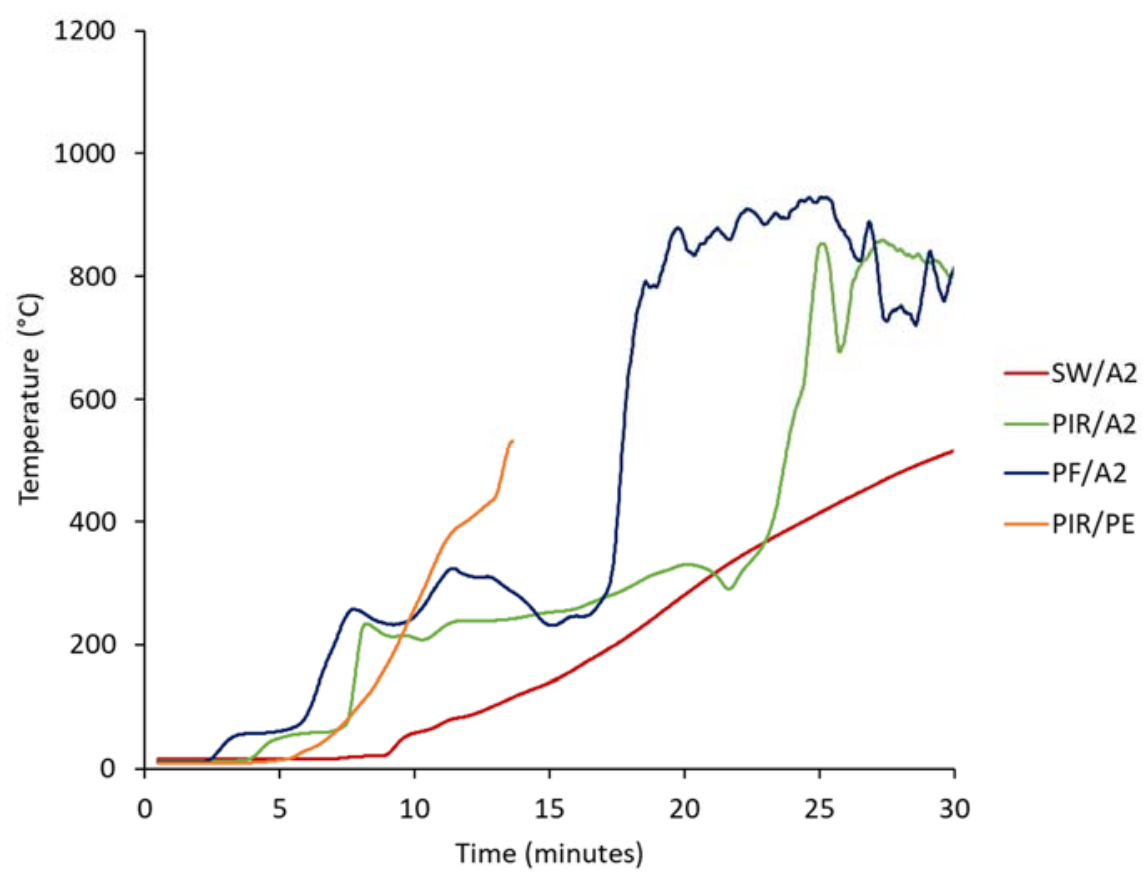

Figure 9 Temperature at midpoint of insulation (TC3)

\subsection{Kitchen Vent Duct}

Figure 10 shows the temperatures in the kitchen vent duct. Superficially, the temperature profiles look similar to Figure 9, where closer inspection shows the PF/A2 and PIR/A2 rapid temperature rises have been reversed.

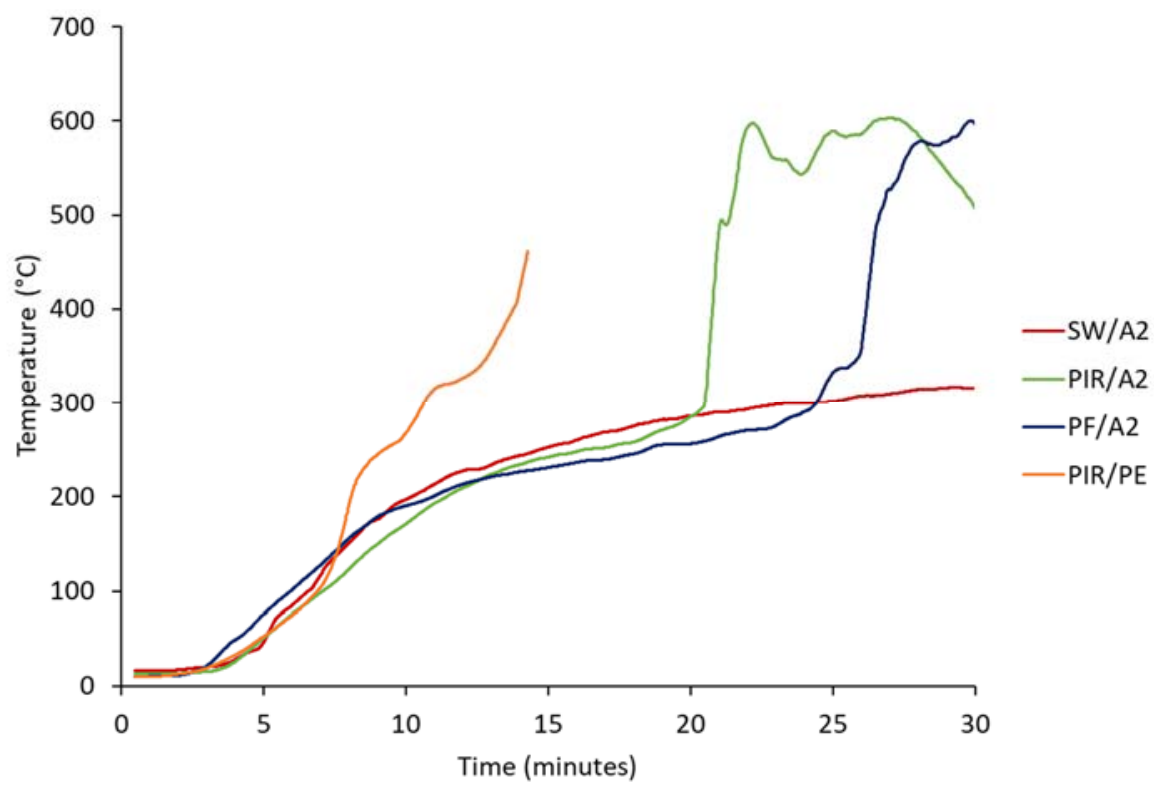

Figure 10 Temperature within Kitchen Vent (TC5)

It can be seen that once the fire reaches the section of the façade containing the vent, as the ACM panels disintegrate, the temperature sharply increases in the duct. The cavity barriers were ineffective without the ACM and the hot smoke and gases entered the vent section. The cavity temperatures are broadly similar for each test $\left(\sim 800^{\circ} \mathrm{C}\right)$, but the temperature in the vent is much more dependent on the burning insulation within the façade and the presence of a vertical rail 
which has helped to isolate the vent section. For PIR/PE, where the ACM panels and the insulation burnt most quickly, the temperature in the kitchen vent increased fastest of all the façades, reaching $450^{\circ} \mathrm{C}$ in 13 minutes. For SW/A2, although the ACM panels above the combustion chamber melted and fell from the wall, the temperature in the vent only increased to around $300{ }^{\circ} \mathrm{C}$, probably because the ACM panels and support rail isolating the vent section remained intact. For PIR/A2 the duct temperature increased sharply to $600^{\circ} \mathrm{C}$ with the combined effect of the wood crib and burning insulation, around 2 minutes after the centre insulation slab fell from the wall, possibly due to the vertical aluminium rail melting as the temperature in the cavity increased. PF/A2 panels became dislodged after 17 minutes, and the temperature in the duct increased sharply to $600{ }^{\circ} \mathrm{C}$ after around 26 minutes. This delay in the temperature increase is probably due to the effect of protection from the vertical rail and dependent on the extent of insulation burning within the cavity since ACM panels around the duct remained intact.

\subsection{Heat Release}

The temperature, oxygen concentration and effluent flow in the main extraction duct were measured for the first $30 \mathrm{~min}$ of the test. The large amount of water vapour resulting from extinguishment of the wood crib prevented meaningful data from being recorded after that time. These data have been used to calculate the heat release rate during each test, shown in Figure 11. Heat release rate has been calculated for PIR/PE based on estimated concentrations of oxygen up to $11.5 \mathrm{~min}$.

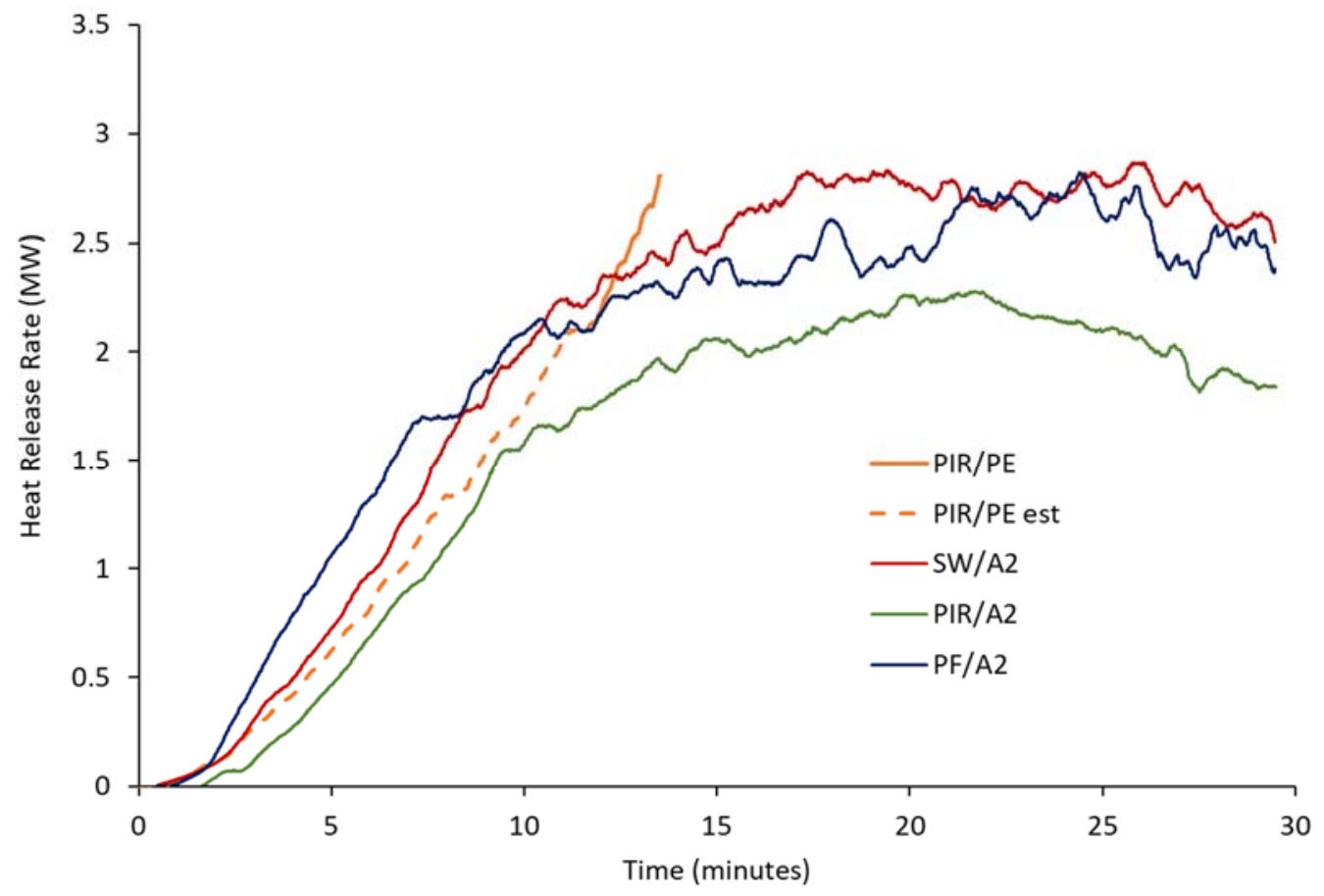

Figure 11 Heat release rates

The calculated heat release rates (HRR) were within the range expected to be produced by the wood crib (a peak rate of $3 \pm 0.5 \mathrm{MW}$ ) [3]. The data show that for PIR/PE the heat release continued to increase after around $10 \mathrm{~min}$, as the fire started to involve the façade products. In the other three ACM-A2 tests the HRR is dominated by the wood crib. Since significant burning of the PIR foam was observed, where the SW/A2 is essentially non-combustible, the SW/A2 heat release should be 
smaller. However, the heat release rate measurements were dependent on the air velocity measurements in the duct $\left(13.8 \pm 0.6 ; 13.8 \pm 0.6\right.$; and $14.8 \pm 0.8 \mathrm{~m} \mathrm{~s}^{-1}$ for SW; PIR; and PF respectively) and the oxygen concentrations (13.4 $\pm 0.3 ; 14.9 \pm 0.4$; and $14.4 \pm 0.4 \%$ for SW; PIR and PF respectively) giving average HRR measurements and uncertainties of $2.69 \pm 0.23 ; 2.12 \pm 0.22$; and $2.51 \pm 0.27$ for SW; PIR and PF respectively. It appears that the measurement uncertainty was similar to the difference observed between individual façade products. The rank order heat release rate data is generally not in good agreement with the thermocouple data. This is likely due to entrainment of fresh air into the smoke extract system and would also be dependent on wind speed and direction on the day of the test.

\subsection{Comparison to other tests}

The tests reported in current study used typical building design and installation practice. In 2018, the Department for Communities and Local Government (DCLG) (now the Ministry of Housing and Local Government (MHCLG)) commissioned a series of BS 8414-1 tests on a set of building façades in the burn hall at BRE in the UK. The test construction was described in the reports and was not representative of typical building design and practice [8]. Of these tests, three involved the same combinations of ACM and insulation materials as our tests: PIR/PE [18], PIR/A2 [19] and SW/A2 [20]. Our remaining combination, PF/A2, was not included in the DCLG tests. In addition, another study, carried out in Croatia, reported by Čolić, featured large scale tests of ACM-A2 panels with PIR, phenolic foam and stone wool insulation [17]. The tests were carried out according to BS 8414-1 on a standard $8 \mathrm{~m}$ high test wall, and conducted outdoors, also using typical building industry design and practice. The purpose of this section is to compare our test results with those using design and fabrication typical of fire test laboratory practice, and with those conducted outdoors. In order to benchmark the current tests against these published data, we compared the damage to test walls from photographs and temperatures from some of the similarly positioned thermocouples. For all the data presented, the start time $(t=0 \mathrm{~s})$ is when a flame is applied to the white spirit-soaked strips within the wood crib (in BS 8414 the start time is defined as when a level 1 thermocouple reaches $200{ }^{\circ} \mathrm{C}$ ). The following figures show the temperature data $2.5 \mathrm{~m}$ above the combustion chamber (centre front face, TC 1 and wing, TC 4) from the tests reported in this work, labelled FPA, compared with level 1 data from the DCLG and Čolić. 


\subsubsection{PIR/A2}

\subsubsection{Temperatures}

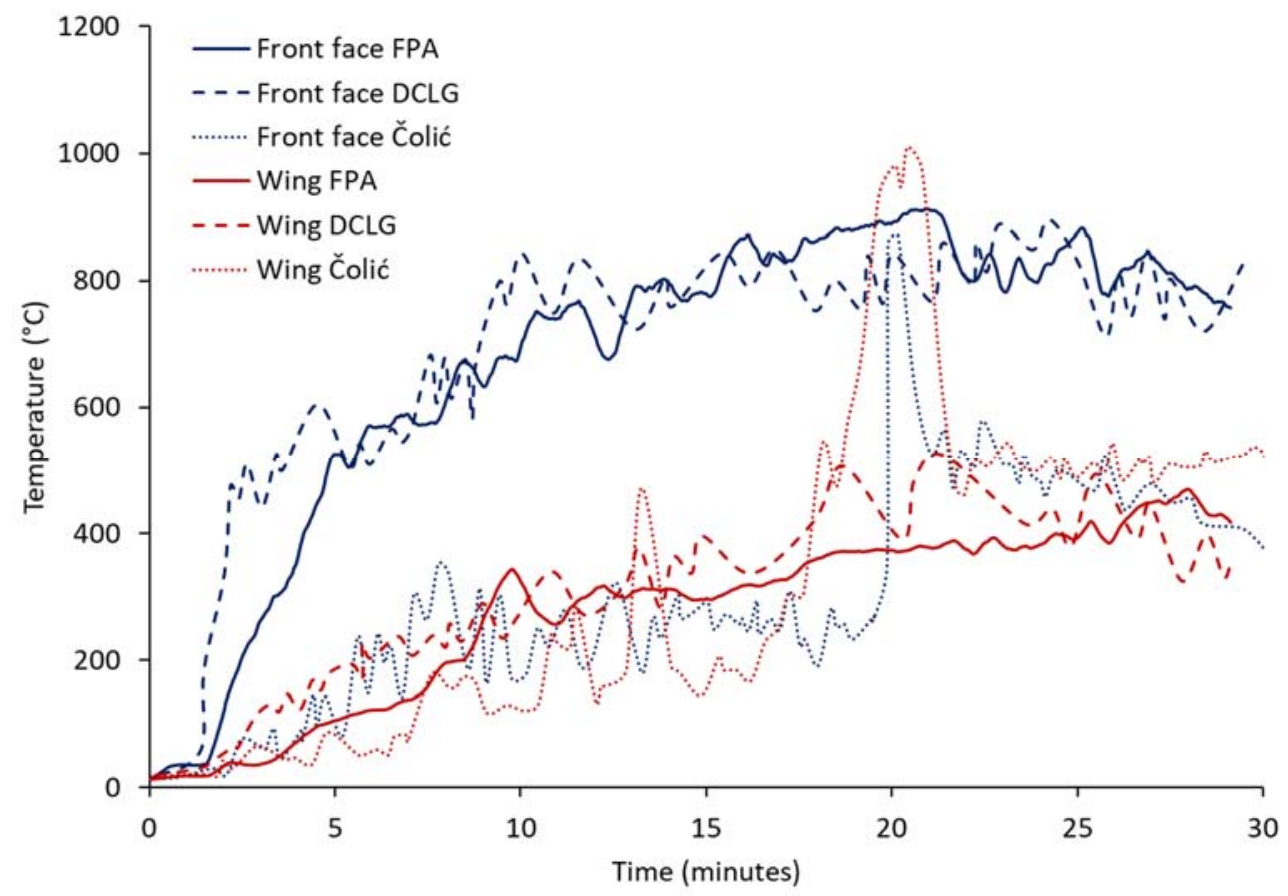

Figure 12 PIR/A2 FPA, DCLG and Čolić temperatures comparison [17, 19]

Figure 12 shows the level 1 temperature data for PIR/A2. Generally, for the DCLG and FPA tests the temperatures were similar throughout the first 30 min suggesting that the fire growth rate was similar, although the temperatures increased at a faster rate during the initial stages (2 to 5 min) for the DCLG tests. The Čolić data show a significantly lower front face temperature (albeit from a different test) than either the DCLG and FPA test data, followed by a sharp and short-lived increase at 20 to $21 \mathrm{~min}$. This is likely to be due to the tests being conducted outdoors because the fire growth rate is highly dependent on wind speed and direction on the day of the test. In contrast, the wing temperature test data shows acceptable agreement between the three tests until 18 min when a similar short-lived increase is observed in the Čolić data. It should be noted that PIR/A2 passed the DCLG test and only passed the Čolić test with additional cavity barriers.

\subsubsection{Burn area}

The photographs in Figure 13 show the burn areas for the FPA, DCLG and Čolic tests for PIR/A2. The burn areas show that the panels have burnt or fallen from the wall and failed to protect the underlying insulation from fire. The burn areas for all tests show that the damage is most severe in the area directly above the combustion chamber. In this area, the ACM panels are missing up to the $5 \mathrm{~m}$ point in all three tests. In the case of the DCLG test, charred PIR remains attached to the wall, suggesting more resilient mountings were used, whereas for our tests and the Čolić tests some PIR is missing and the masonry wall can be seen. Damage has occurred to the wings of all walls, most severe for our test where some of the ACM panels are damaged and partially missing, despite the lowest wing temperatures. The ACM on the wing of the DCLG and Čolić tests has been damaged on the surface, but has remained intact. The DCLG and Čolić test walls show that the damage to the wall, and missing ACM, above the combustion chamber extends beyond $5 \mathrm{~m}$. 

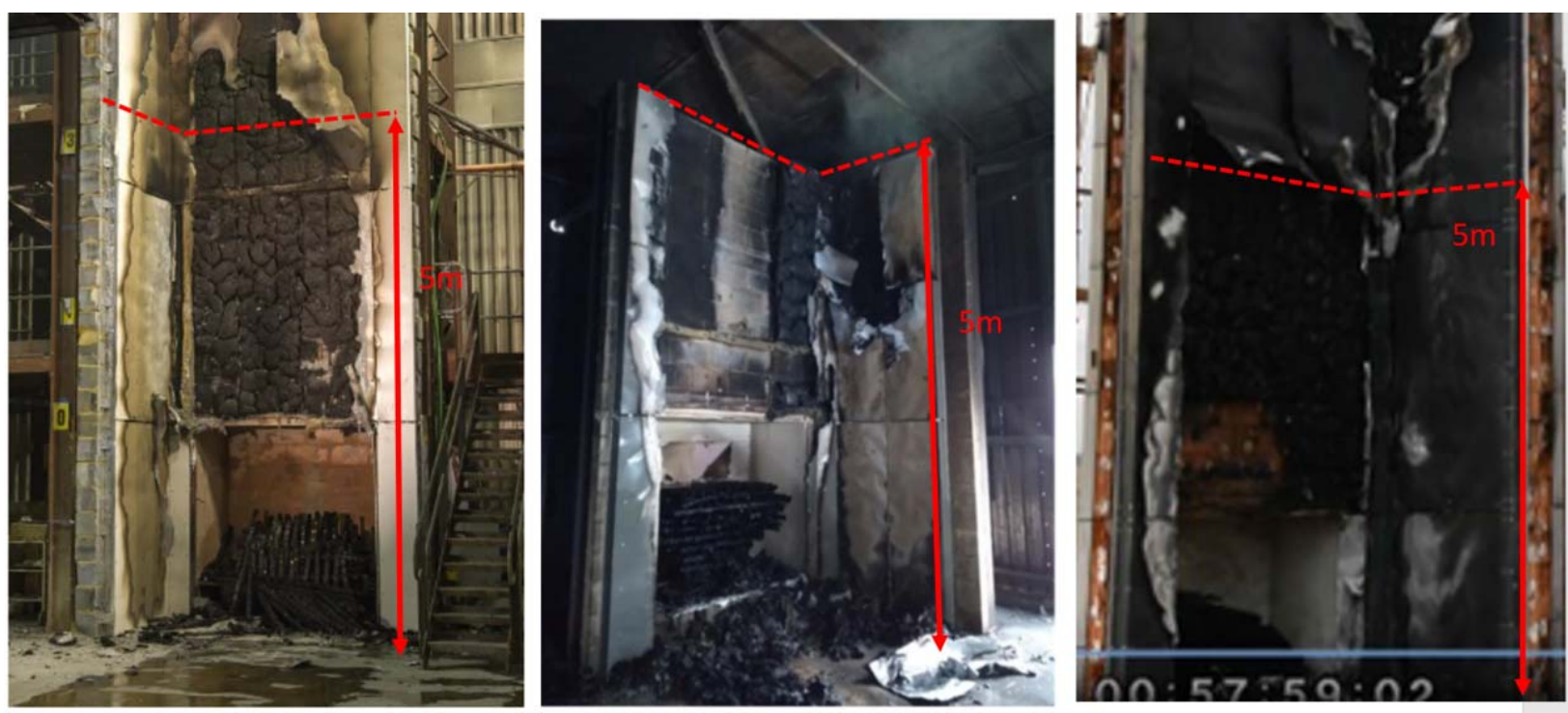

Figure 13 PIR/A2 comparison of burn area DCLG (left), FPA (centre) and Čolić (right) [17, 19]

\subsubsection{SW/A2}

\subsubsection{Temperatures}

Figure 14 shows the temperature data for the current, DCLG and Čolić tests for SW/A2. The temperatures at the front face increased at a similar rate for all the tests, with the temperatures for the Čolić tests being lower towards the end of the 30 min period. Again, the temperature increased slightly faster in the initial stages (first $5 \mathrm{~min}$ ) for the DCLG test. The wing temperatures were similar for our tests and DCLG tests throughout the 30 min period, no Čolić wing data was available for comparison.

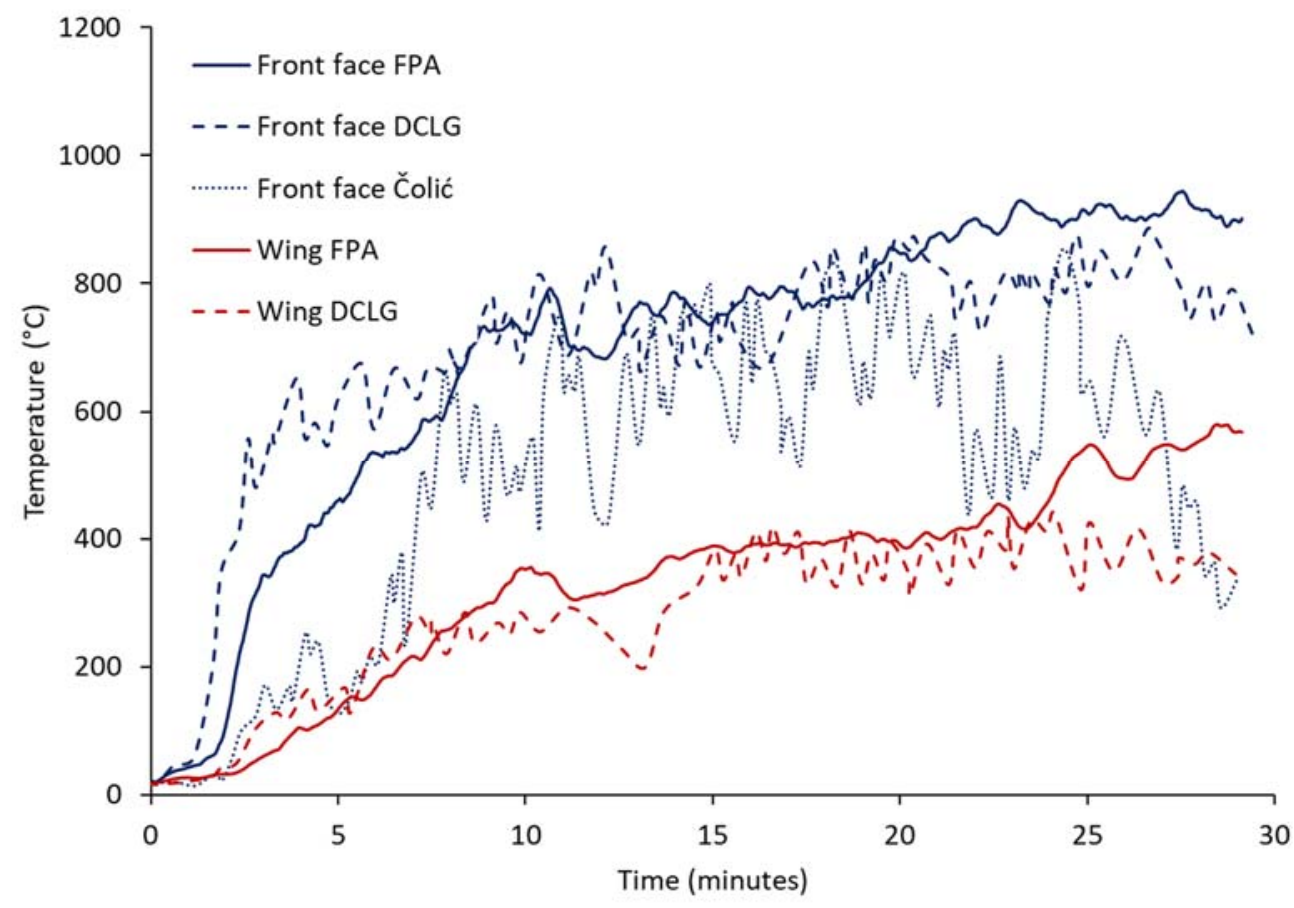




\subsubsection{Burn area}

Figure 15 shows photographs of the burn areas for all tests. In the area directly above the combustion chamber, the ACM panels have burnt away and exposed the underlying stone wool insulation. The ACM panels on the wings have been damaged in all tests, with our test wall being more severely damaged, again exposing the insulation. The wings of the DCLG and Čolić test walls have some damage on the surface of the ACM but the ACM panels have remained attached to the walls. In all tests reported the SW insulation remained attached.
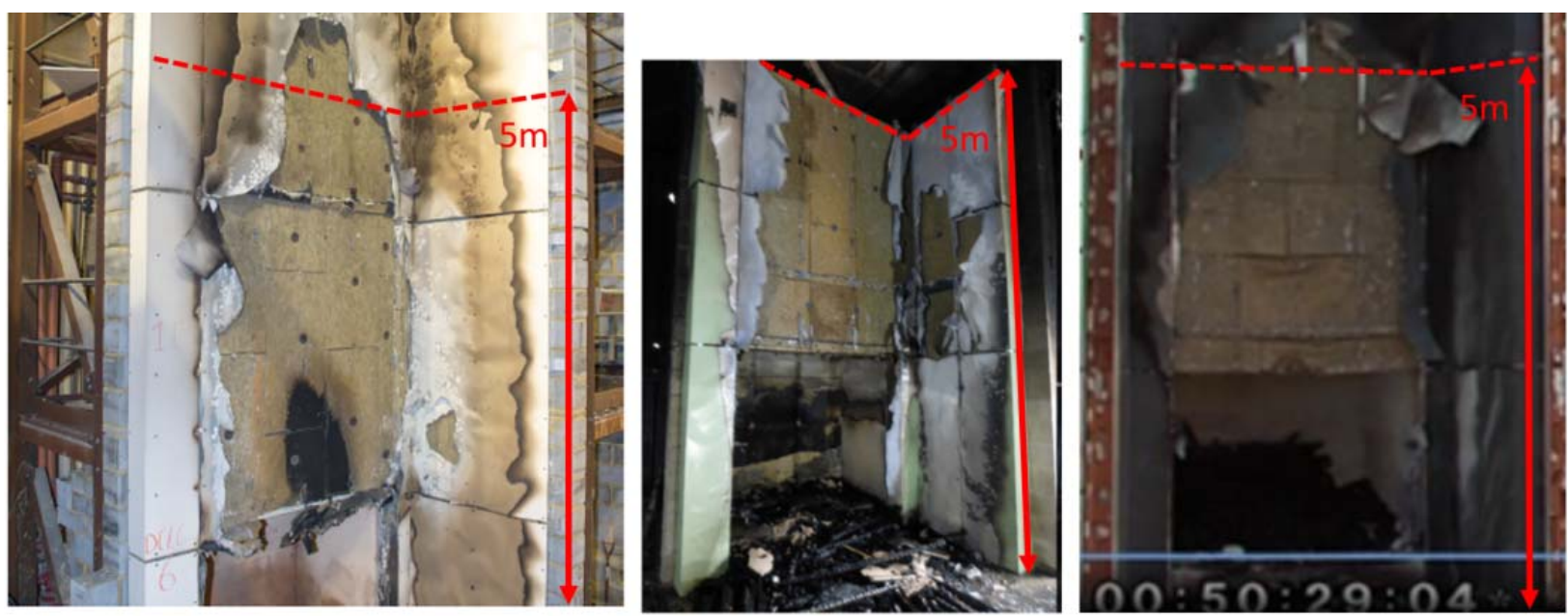

Figure 15 SW/A2 comparison of burn area DCLG (left), FPA (centre) and Čolić (right) [17, 20]

\subsubsection{PF/A2}

\subsubsection{Temperatures}

Figure 16 shows the temperature data from the current study and Čolić. The front face temperatures were lower in the initial stages for Čolić but similar after the first $15 \mathrm{~min}$. No Čolić wing data was available and DCLG did not carry out a test of this combination. This combination of PF/A2 only passed the Čolić test when additional cavity barriers were used. 


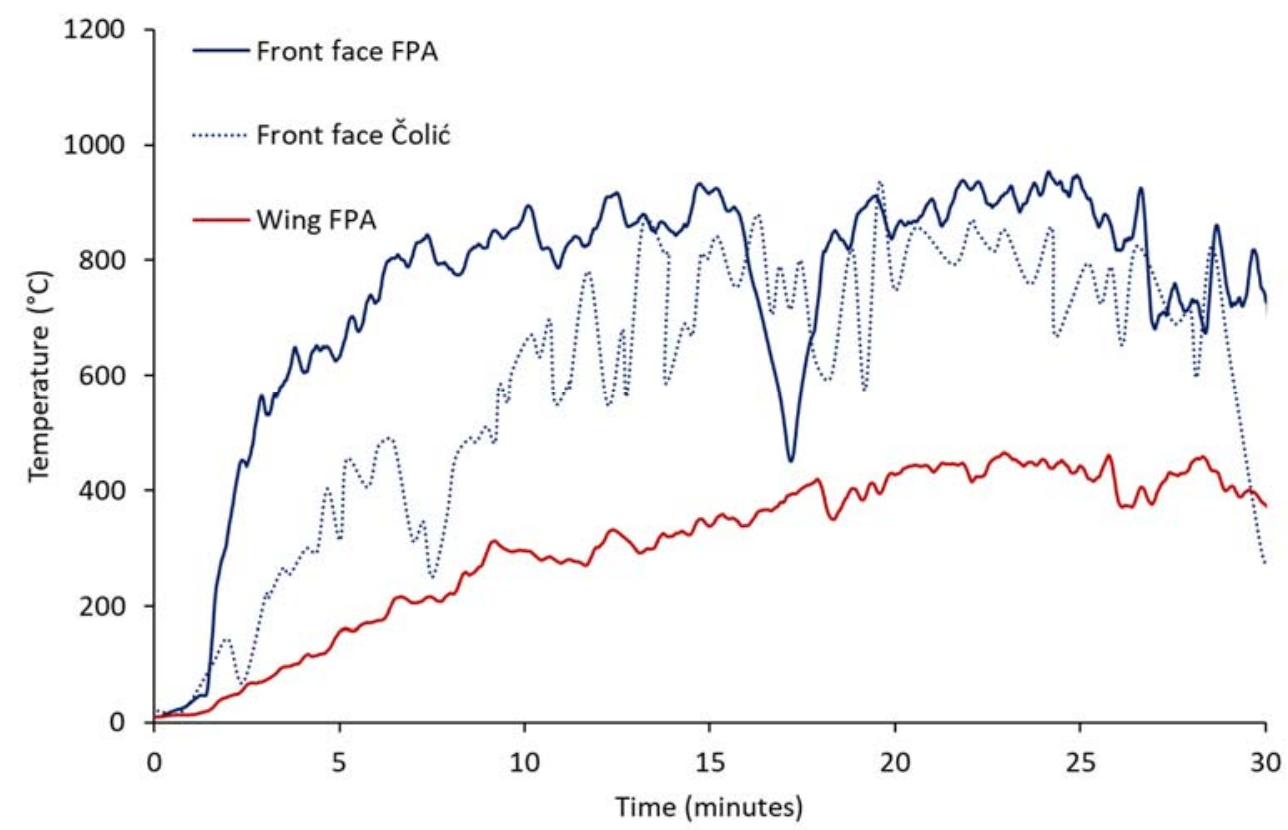

Figure 16 PF/A2 FPA and Čolić temperatures comparison [17]

\subsubsection{Burn area}

The photographs in Figure 17 show a similar pattern of damage to both façades. The area directly above the combustion chamber has suffered the most damage, with ACM panels and PF insulation having fallen from the walls during the tests. The Čolić façade shows the damage extending well above the $5 \mathrm{~m}$ mark. The FPA wing has been damaged but the ACM has remained in place, however, some of the ACM has started to detach from the wing of the Čolić façade.

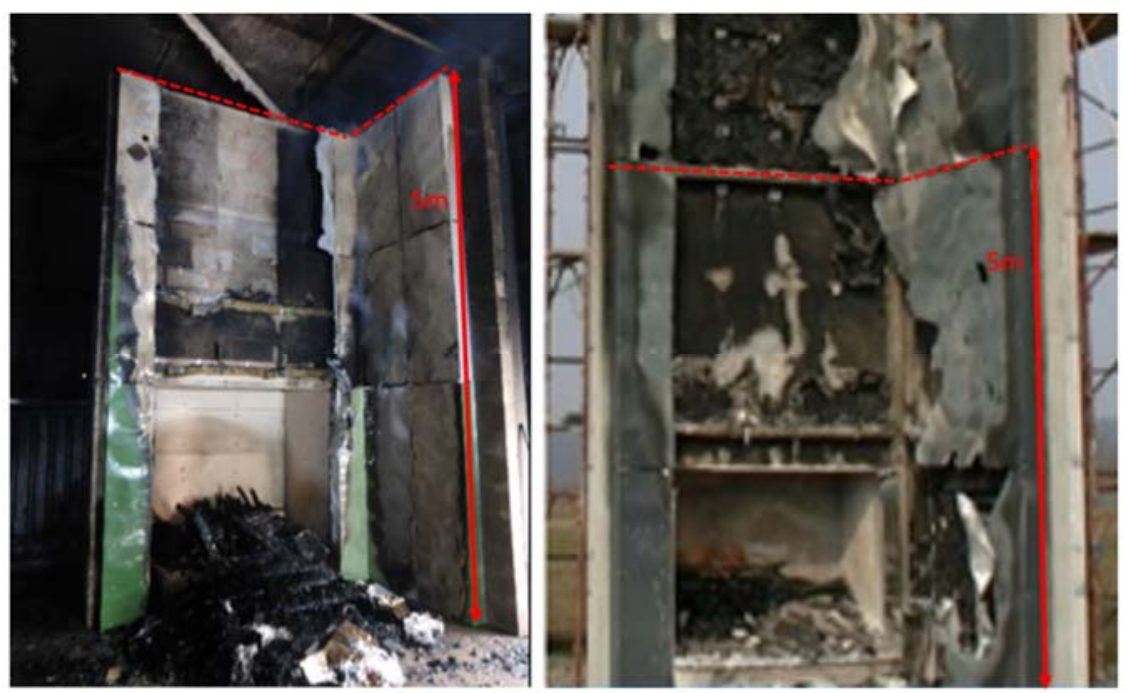

Figure 17 PF/A2 comparison of burn area Čolić (left) and FPA (right) [17] 


\subsubsection{PIR/PE}

\subsubsection{Temperatures}

Figure 18 shows that the temperature increases at both the centre of the front face and the wing were similar for the duration of the tests. This material combination of PIR/PE resulted in temperatures increasing at a faster rate than for any other test. The DCLG test was stopped sooner ( $8 \mathrm{~min}$ ) than the FPA test $(13.5 \mathrm{~min})$, but the data show that the fire growth was similar for the first 8 minutes of both tests.

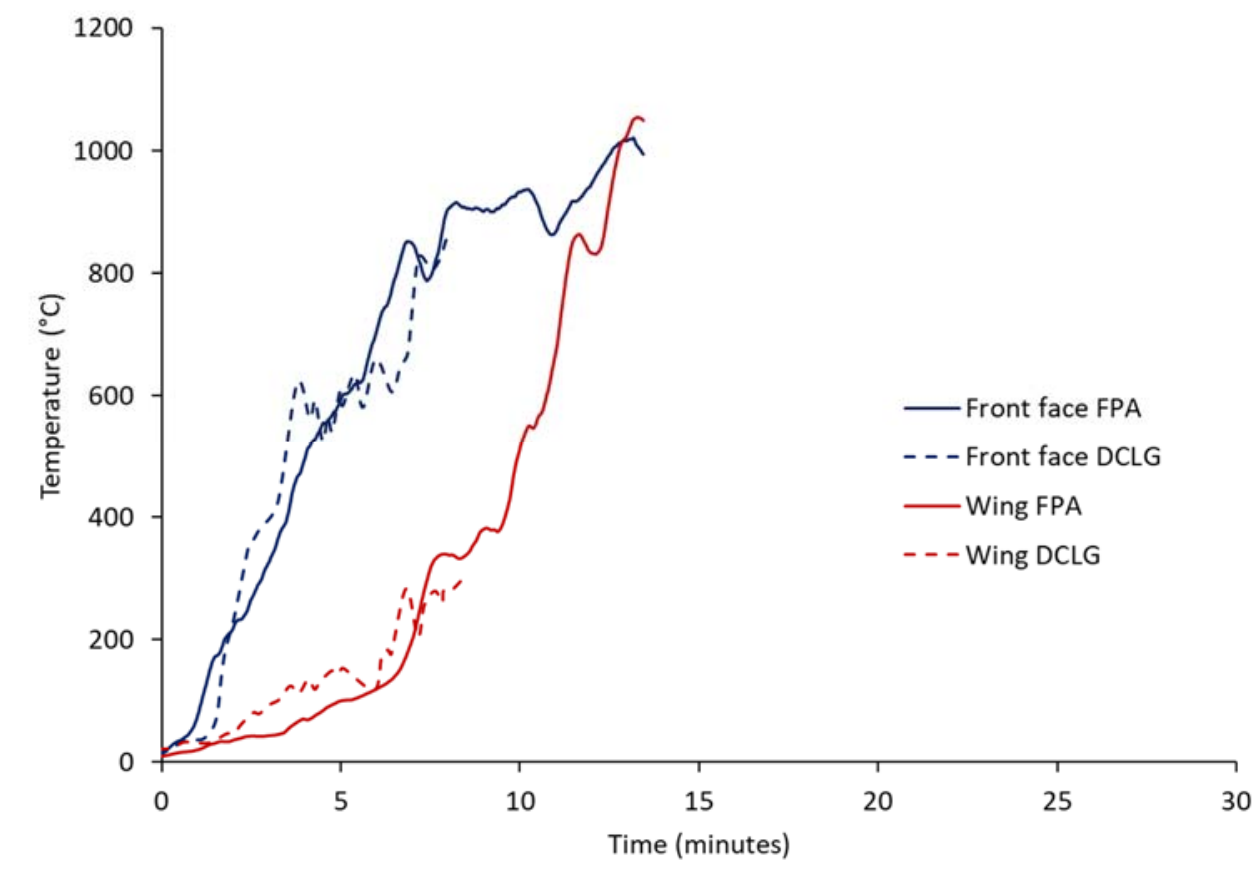

Figure 18 PIR/PE FPA and DCLG comparison [18]

Overall, the FPA and DCLG temperature data was similar for each test and the Čolić temperatures were generally lower, at the start of the tests, and for PIR/A2 lower for most of the test, but with a sharp peak around $20 \mathrm{~min}$. This is likely to be due to the Čolić tests being performed outdoors resulting in slower initial fire growth of the crib and a subsequent delay in the onset of ignition of the combustible insulation. The photographs showed that the burn areas were similar for each test, regardless of whether they were conducted indoors or outdoors and regardless of whether the L1 temperatures were similar. The comparison shows little difference in the temperature data between the "test laboratory" and "typical building industry" design and construction. In contrast, the photographs of the burn damage show loss of PIR panels from the typical construction, where they remained in place in the test laboratory construction.

\subsection{Calculation of energy release.}

The heat release on complete combustion of the façade system has been estimated from its chemical composition and literature values, and from the measured values reported previously [5]. Using literature values for the density and heat of combustion of PE, PIR and aluminium respectively of $0.95 \mathrm{~g} \mathrm{~cm}^{-3}$ and $43 \mathrm{~kJ} \mathrm{~g}^{-1} ; 0.0332 \mathrm{~g} \mathrm{~cm}^{-3}$ and $25 \mathrm{~kJ} \mathrm{~g}^{-1}$; and $2.7 \mathrm{~g} \mathrm{~cm}^{-3}$ and $31 \mathrm{~kJ} \mathrm{~g}^{-1}$, the heat release per unit area of façade on complete combustion of the PE is $123 \mathrm{MJ} \mathrm{m}^{-2}$, for PIR it is $83 \mathrm{MJ} \mathrm{m}^{-2}$, and for aluminium it is $84 \mathrm{MJ} \mathrm{m}^{-2}$. Thus, on complete combustion, each square metre of the façade system can contribute $206 \mathrm{MJ}$ (excluding aluminium) to $290 \mathrm{MJ}$ (including aluminium) to the fire. Our observations after the large-scale tests were that most of the aluminium lost from the façade 
seemed to have melted into solid lumps on the floor, suggesting that its oxidation did not contribute significantly to the heat release.

In order to understand the burning behaviour of different combinations of building products, estimates of peak and total heat release have been made from small-scale tests. Table 4 shows the contribution to the heat release from each component of the façade system, as measured previously, (or reported in Table 3) employing the approach described above. This shows the small contribution made to fire growth from the non-combustible components and the larger contribution from the combustible components, whether quantified as peak HRR or total heat release.

Table 4 Potential heat release from each component of the façade system

\begin{tabular}{lccl}
\hline & \multicolumn{2}{l}{ Cone calorimeter data } & MCC data \\
\hline Sample & Peak HRR & $\begin{array}{l}\text { Total heat } \\
\text { release } \\
/ \mathrm{MJ} \mathrm{m}^{-2}\end{array}$ & $\begin{array}{l}\text { Total heat } \\
\text { release } \\
/ \mathrm{MJ} \mathrm{m}^{-2}\end{array}$ \\
\hline ACM_PE & 1123 & 106.6 & 119 \\
ACM_A2 & 13.8 & 2.57 & 11 \\
PF & 62.0 & 17.56 & 74 \\
PIR & 100 & 14.9 & 72 \\
SW & 5.6 & 0.11 & 17 \\
\hline
\end{tabular}

Table 5 shows the potential contribution to flame spread based on the data measured here. Two simple approaches were used. The first calculated the total energy release from the heat of combustion data, per $\mathrm{m}^{2}$ of façade, from MCC method B data, and cone calorimetry. The second used the sum of the pHRR from the products, in $\mathrm{kW} \mathrm{m}^{-2}$ from cone calorimetry, since the pHRR is thought to be the best indicator of potential fire growth [21].

Table 5 Predicted behaviour of façade product combinations

\begin{tabular}{|c|c|c|c|}
\hline $\begin{array}{l}\text { Products in } \\
\text { test }\end{array}$ & $\begin{array}{l}\Sigma(\text { Peak Heat } \\
\text { Release Rate) } \\
\text { cone calorimeter } \\
/ \mathbf{k W ~ m}^{-2}\end{array}$ & $\begin{array}{l}\Sigma \text { (Heat of } \\
\text { combustion per } \\
\text { unit area) cone } \\
\text { calorimeter } \\
/ \mathrm{kW} \mathrm{m}^{-2}\end{array}$ & $\begin{array}{l}\Sigma \text { (Heat of } \\
\text { combustion per } \\
\text { unit area) MCC } \\
\text { method B } \\
/ \mathrm{kW} \mathrm{m}^{-2}\end{array}$ \\
\hline SW/A2 & 19 & 3 & 20 \\
\hline PIR/A2 & 114 & 16.5 & 83 \\
\hline PF/A2 & 77 & 20.5 & 85 \\
\hline PIR/PE & 1223 & 121.5 & 191 \\
\hline
\end{tabular}

The quantitative data used from bench-scale tests actually provides more useful quantitative information than the large-scale demonstration of burning behaviour reported here. For example, the similarity of performance for PF and PIR with ACM-A2 can be seen from the bench scale data. However, the bench-scale data (such as cone calorimetry in which the $0.5 \mathrm{~mm}$ aluminium sheets remained entirely intact, with only the filling burning (even for ACM-PE) do not provide any information on the complete loss of integrity of the ACM-A2 when exposed to a $3 \mathrm{MW}$ burning crib, and its inability to offer any protection to the combustible insulation. 


\section{Conclusions}

Four large-scale façade flammability tests were undertaken using a reduced-height BS 8414 test rig. The three tests using non-combustible ACM-A2 were run for the full hour, the test with ACM-PE was stopped for safety reasons in accordance with the BS 8414 standard. The fire growth of the PIR/PE combination was alarmingly fast, resulting in a rapidly-developing, severe fire. The shower of burning droplets of molten PE escaping from the panels significantly increased the heat release rate and fire growth rate. Unfortunately, the need for early extinction of the fire limits the comparability of the data with the other tests.

In the three ACM-A2 experiments, the fire behaviour of the reduced height BS 8414 test was dominated by the burning behaviour of the $3 \mathrm{MW}$ wood crib, providing relatively little opportunity to discriminate between non-combustible and combustible insulation systems in the $3 \mathrm{~m}$ above the combustion chamber. The "fire-safe" ACM-A2 product, although not making a significant contribution to the fire growth in its own right, nevertheless failed to protect the combustible insulation in the PIR/A2 and PF/A2 tests, as it was lost from about $40 \%$ the facade through a combination of detachment, softening, melting, and possibly also burning of the aluminium. This has significant implications for building fire safety, where non-combustible ACM panels are used in combination with combustible insulation in rainscreen-type facades. In particular, as the ACM-A2 combinations with certain types of PIR and phenolic foam were deemed to be compliant with the building regulations as a result of the DCLG tests, this failing highlights a deficiency in the regulatory system.

The potential for fire to spread within the façade, possibly out of sight, or access to firefighters' hoses, should be limited by the cavity barriers. However, the effectiveness of any cavity barrier is completely dependent on the integrity of the panels which they seal against. As soon as the ACM panels start to distort, and once the panels become detached, the cavity barriers are completely ineffective. This was particularly evident with the ACM-PE panels, which were destroyed within the first 8 minutes of ignition.

The comparison of temperature and burn area damage to the façade from similar tests of SW/A2, PIR/A2 and PF/A2 in the DCLG/BRE and Croatian tests showed significant agreement, although the L1 temperature data showed differences on three different test walls, two indoor and one outdoor. From the temperature measurements, there seemed little difference in the façade performance, between specially constructed test facades, and those built using typical design and practice, while the visual inspection of burn damage showed significant differences. Moreover, the significant differences observed in temperature measurements between indoor and outdoor, suggest they are not a reliable indicator of fire progress.

The comparative bench-scale data provides a quantitative comparison of the contribution from the individual façade components, but fails to convey any information on the failure of the ACM-A2, and its consequent inability to protect the combustible foam from fire. The very clear public safety message from this work is the danger of combining non-combustible, but also non-fire resistant cladding panels, such as ACM-A2, with combustible insulation in a rainscreen façade.

Although bench-scale methods adequately assess the differences between combustible and noncombustible products, the fire performance of rainscreen façades with combustible components is too complex to be adequately assessed on a bench-scale or materials' chemistry basis. The ACM-A2 
panels and aluminium support rails, which lose strength around $500^{\circ} \mathrm{C}$, and melt at $600{ }^{\circ} \mathrm{C}$, also require adequate assessment of their fire resistance (maintenance of structural integrity in a fire). The use of cavity barriers, which rely entirely on the integrity of the outer panel for their effectiveness, emphasises the importance of the fire resistance aspect. The ISO 13785-1 testing, described by Guillaume ${ }^{16}$, uses such a small heat source it is unsuitable for testing the fire performance of rainscreen façades. While the $3 \mathrm{MW}$ crib of BS 8414 destroys large areas of ACM-A2, the $100 \mathrm{~kW}$ source of ISO 13785-1 leaves it undamaged. (The reduced scale approach of ISO 13785-1 might be valid if special ACM-A2 were manufactured with the thickness of its aluminium sheets and filling reduced in proportion to the height reduction from $9 \mathrm{~m}$ to $2.4 \mathrm{~m}$ ). The data from these tests was then used by Guillaume to model the flame spread in Grenfell Tower, suggesting that the combustible façade made no significant contribution. In our tests, the combustible insulation (PIR or PF) had burnt all the way to the top of the test rig $(5 \mathrm{~m})$ and became detached from the wall, with a similar degree of damage to the ACM-A2 being observed for the stone wool insulated test. In contrast, in the DCLG tests for ACM-A2 with PIR and stone wool, the ACM-A2 was destroyed to a greater height when tested with PIR insulation $(>6 \mathrm{~m})$ compared to stone wool $(\sim 5 \mathrm{~m})^{19,20}$. It is difficult to say whether, in a real building, a combination of ACM-A2 and PIR could result in a selfsustaining fire, particularly if the original fire, assumed in BS 8414 to be a post-flashover apartment, were to burn for more than $30 \mathrm{~min}$ or with greater heat flux than $3 \mathrm{MW}$.

A summary report [4], based on this study, was submitted to the UK government prior to the change in Building Regulations. The December 2018 change, banning the use of any combustible products on residential buildings over $18 \mathrm{~m}$ tall, stipulated that fire performance must be Euroclass A2 s1 d0 or better, on the external walls of new or refurbished buildings. The ban does not include hotels, offices, hospitals or buildings below $18 \mathrm{~m}$, and was not retrospective.

\section{Acknowledgements}

This research did not receive any specific grant from funding agencies in the public, commercial, or not-for-profit sectors. We very gratefully acknowledge the RISCAuthority/Fire Protection Association (FPA) for providing facilities and arranging construction of the test walls, Ash and Lacy Ltd for provision of ACM panelling and fixtures, and to Arup for providing designs and drawings of the test wall facades.

\section{References}

[1] The Building Regulations 2010, Fire Safety Approved Document B. Volume 1: Dwellings. 2019 Edition. [Accessed 21/04/20]. https://assets.publishing.service.gov.uk/government/uploads/system/uploads/attachment d ata/file/832631/Approved Document B fire safety volume 1 - 2019 edition.pdf

[2] Colwell, S., and Baker, T., BR135: Fire Performance of external thermal insulation for walls of multistorey buildings, 3rd Edition, BRE Trust, Watford, 2013.

[3] BS 8414-1:2015+A1:2017 Fire performance of external cladding systems. Test method for nonloadbearing external cladding systems applied to the masonry face of a building, BSI, London. 
[4] RISCAuthority Interim Project Report. Occupant exposure to fires in rain-screen cladding systems. November 2018. https://www.thefpa.co.uk/news/news/news detail.fpa-toxicsmoke-testing-results.html

[5] McKenna, S. T., Jones, N., Peck, G., Dickens, K., Pawelec, W., Oradei, S., Harris, S., Stec A. A., and Hull, T. R. Fire behaviour of modern facade matrerials - Understanding the Grenfell Tower fire, (2019) Journal of Hazardous Materials, 368, pp. 115-123.

https://www.doi.org/10.1016/j.jhazmat.2018.12.077

[6] Taylor, W. Fire spread in concealed foamed plastic insulation, (1983) Fire Technology 19, pp. 192-203. https://doi.org/10.1007/BF02378699

[7] Babrauskas, V., The Grenfell Tower Fire and Fire Safety Materials Testing, Fire Engineering. 2018. https://www.fireengineering.com/articles/print/volume-171/issue-1/features/thegrenfell-tower-fire-and-fire-safety-materials-testing.html

[8] Schulz, J., Kent, D., Crimi, A., Glockling, J. L. D., Hull, T.R., A critical review of the UK's regulatory regime for combustible façades, (2020), Fire Technology.

https://doi.org/10.1007/s10694-020-00993-z

[9] Bonner, M., and Rein, G. Flammability and multi-objective performance of building facades: Towards optimum design, International Journal of High-Rise Buildings. 7: 4, pp. 363-374. 2018. https://www.doi.org/10.21022/IJHRB.2018.7.4.363

[10] Lane, B. Grenfell Tower Inquiry. Phase 1 - Expert report, 2018. [Accessed 21/04/20]. https://www.grenfelltowerinquiry.org.uk/evidence/dr-barbara-lanes-expert-report

[11] MHCLG Government Building Safety Programme - Monthly Data Release 31st January 2020. [Accessed 20/04/20]. https://assets.publishing.service.gov.uk/government/uploads/system/uploads/attachment d ata/file/865483/Building Safety Data Release January 2020.pdf

[12] Acceptability of common wall constructions containing combustible materials in high rise buildings, NHBC Technical Guidance Note, July 2016.

[13] ASTM D7309-13. Standard Test Method for Determining Flammability Characteristics of Plastics and Other Solid Materials Using Microscale Combustion Calorimetry, ASTM International, West Conshohocken, PA, 2013.

[14] ISO 5660-1:2015 Reaction-to-fire tests - Heat release, smoke production and mass loss rate - Part 1: Heat release rate (cone calorimeter method) and smoke production rate (dynamic measurement), ISO, Geneva.

[15] BS 8414-1:2015+A1:2017, Fire Performance of External Facade Systems. Part 1: Test method for non-loadbearing external cladding systems applied to the masonry face of a building, 2017. British Standards Institution, London.

[16] Guillaume, E., Fateh, T., Schillinger, R., Chiva, R., Ukleja, S. Study of fire behaviour of facade mock-ups equipped with aluminium composite material-based claddings, using intermediatescale test method, (2018) Fire and Materials, 42 (5), pp. 561-577. https://doi.org/10.1002/fam.2635

[17] Čolić, A. and Pečur, I. B., Influence of horizontal and vertical varriers on fire development for ventilated façades, Fire Technology. 2020. https://doi.org/10.1007/s10694-020-00950-w

[18] DCLG Test 1: BS 8414-1:2015 + A1:2017. BRE Global client report, Sept. 2017. https://assets.publishing.service.gov.uk/government/uploads/system/uploads/attachment d ata/file/648789/DCLGtest1 BS 8414 Part 1 test report Issue1.2.pdf [Accessed 04/05/20].

[19] DCLG Test 5: BS 8414-1:2015 + A1:2017. BRE Global client report, Sept. 2017. https://assets.publishing.service.gov.uk/government/uploads/system/uploads/attachment d ata/file/648793/DCLGtest5 BS 8414 Part 1 test report Issue 1.2.pdf [Accessed 04/05/20]. 
[20] DCLG Test 6: BS 8414-1:2015 + A1:2017. BRE Global client report, Sept. 2017.

https://assets.publishing.service.gov.uk/government/uploads/system/uploads/attachment d ata/file/648794/DCLGtest6 BS8414 Part 1 test report Issue 1.1.pdf [Accessed 04/05/20].

[21] Babrauskas, V., Peacock, R.D., Heat release rate: The single most important variable in fire hazard, (1992) Fire Safety Journal, 18 (3), pp. 255-272. https://doi.org/10.1016/0379$\underline{7112(92) 90019-9}$ 